certainly, of the salutary power of inflammation, and in this aspect it assuredly acts as a remedial process.

Notwithstanding that adhesion of the injured part of the intestinal canal to the edge of the opening in the parietes of the abdomen took place, as it were, by the first intention, still the freces pressed involuntarily out by the artificial anus partly, and partly by the natural outlet. This unpleasant and painful disease continued unmitigated for five years, and all the assistance afforded to this patient by my medical friends and myself, during that period; was in vain, and every method of treatment entirely failed of success. In this critical conjuncture the patient was respectfully informed that it seemed to be likely that his complaint was incurable.

About seven months ago I accidentally met the patient in question. I inquired after his health. He replied that his existence was a burden to him, and that all the fæces was now evacuated by the artificial anus at the groin, and that nothing but a little mucus came by the natural passage. On the spur of the moment $I$ urged that he shonld remain in bed for some days to come, and during that period that he should constantly employ a pretty long piece of brown soap, shaped like a large wax candle, besmeared with olive oil, and kept well up in the rectum by a compress, and that in order to provoke the descent (in part at least as formerly) of the freces by the natural passage, I also urged that a cataplasm of beanmeal should at night be kept to the artificial anus, while during the day it was to be dusted over with finely-powdered chalk, and moreover that he should take an alterative course of tincture of gentian and tincture of iodine, say five drops of the latter to a teaspoonful of the former three times daily, followed by castor oil twice a week.

At the time that I urged the employment of the mechanical pressure within the rectum, this measure was solely recommended in order to provoke in part the descent of the fæces towards the natural aperture. But great was my surprise and great was the delight of my patient, when it was found that daily there was less and less fæces passed out of the artificial anus by the agency of the pressure within the rectum, and at the end of two weeks the artificial anus was completely healed by the constant pressure.

After the cure was effected, I began to ascertain the real cause of my success. It was certainly very simple, and obviously quite accidental as far as I am concerned; and although not recommended at the time, it was employed on the basis of scientific data; yet the experience of the event is well calculated to establish the value of the discovery. Thus the constant mechanical pressure of the soap within the rectum, and over the sphincter and levatores ani, caused a constant tenesmus or desire to evacuate the contents of the alimentary canal, just as is produced by volition and the reflex action of the nervous system in the abdominal region during the effort of voluntary straining at stool. Again, in the constant exercise of this tenesmus, or straining as at stool, thus produced by the constant employment of the mechanical pressure, it is obvious that a farther pressure of the parietes of the abdomen is called into constant exercise, whereby a contractile force is further applied to the three membranes of the intestinal canal-viz., the peritonæal, muscular, and villous coats, and thus by the combined contractile agency of all these various tissues was the artificial anus completely cured, solely by pressure.

The patient in question was quite well for four months, and would, as I think, have been quite rid of the unpleasant consequences of the artificial anus during the whole period of his natural life, were it not for an accidental fall into the hold of a vessel, having coals on board, abont three months ago, by which fall he came in contact with an angular piece of coal, which, unfortunately for him, struck him over the very seat of the old artificial anus, and burst the integuments, through which the faces passed out involuntarily and as formerly. Yet the employment of the same remedies as before healed the artificial anus again, in about the same period of time as before noted, and it remained whole for several weeks, and would have remained whole, as I think, also during this patient's natural life; but I must add, and I do so with regret, that within a few weeks my patient happened to be engaged in a tumult with some inebriated friends, and in the fray he received a kick over the artificial anus again, which lately remained re-opened. The patient was then informed that whenever he gave up the vice of drinking ardent spirits to excess, and whenever he was desirous of employing the former remedies, I had not the slightest doubt but the said remedies would be crowned with success, as on the two former occasions.
I have not as yet had any experience of the effects of similar treatment, in cases of artificial anus produced by gangrene of the bowels, called by some practitioners a mortified hernia; but, reasoning from analogy, I should think so, all things bing equal; at any rate the treatment would seem deserving of a trial under similar circumstances.

Upon the whole I have taken the liberty of giving publicity to this case of artificial anus from a penetrating wound, and twice cured by mechanical pressure constantly employed within the rectum, in the hope that my medical friends may be equally fortunate in similar cases. Should this happy and fortunate event be realised in all such cases, I shall feel well satisfied, and certainly fully rewarded.

Ewing-place, Glasgow, Aug. 1853.

\section{CASES OF HYDROPHOBIA TREATED BY ASPARAGUS OFFICINALIS.}

BY DR. A. CHAIRÉTÈS,

INSPECTOR OF THE ROYAL BOTANIC GARDENS AT ATHBNS.

ON the 8th of February, 1851, Anastase Lambarris, a gardener, of about fifty-five years of age, was bitten by a mad $\mathrm{dog}$ in the middle finger of the left hand. According to the practice in like cases among the people the patient had applied to the bite some of the hair taken from the same dog and burnt; the dog itself was burnt, and the man leaped three times over the ashes; lastly, he drank a decoction of the plant called phanéroméai, and then believing himself perfectly cured, returned to his work, and remained in perfect health until the 16th of May following. On the morning of this day he felt first a general malaise, then a disagreeable numbness, which, arising from the spot which had been bitten, extended over the whole arm. It was at this time only that he experienced shivering.

On the morning of the 17 th he began to experience a repugnance for water, which he expressed by saying, "I cannot bear the air of water." Towards noon he sent for two physicians, who recognised the existence of hydrophobia by its unmistakable phenomena. They prescribed calomel and belladonna, but the patient rejected this with bile.

At six A.M. of the 18th I was requested to see him. After hearing the story of his friends, I offered him a glass of water. He took it, and carried it eagerly to his mouth; but scarcely had the liquid touched his lips when a sudden convulsion made him push the glass away, notwithstanding the efforts of the unfortunate man to keep it near his lips. "You see, Sir," said he, "it is all over with me."

I sent to the Botanical Garden for some young shoots of asparagus, which I made him eat one after the other. Deglutition at first was performed with difficulty, and was still further embarrassed by continual ptyalism; but this diffculty gradually subsided. I then left him tolerably reassured, directing his wife to give him nothing but asparagus, whether for medicine or food. After three hours I found him more at ease; he had slept nearly two hours, which he had not done at all for the two preceding nights; and the numbness of his arm was relieved.

During this and the following day the patient swallowed a quantity of asparagus, and his amendment appeared to progress. He slept calmly, and perspired freely. On the evening of the 19th he called for water, and drank half a glassful without difficulty. But at the moment that his wife was making this report to me at my house, a sad scene was going on at home. Some gens-d'arme had introduced themselves into the house, and questioned the son as to the state of the patient. Being told that he was quiet, they said, "Now is the time." The patient overhearing these words, and impressed with the idea that they wished to poison him, became suddenly furious, seized his arms, and flew out of the room stark naked in pursuit of the gens-d'armes. At this moment, meeting my brother, and mistaking him for me, he appealed to him for assistance against these gens-d'armes, who, he said, wished to poison him. The unfortunate man, nalked, breathless, covered with sweat, came to the city, crossed with naked feet the stream, always running, in front of the Church of the Holy Trinity, and entered a café with which he was acquainted, threatening all who came near him to seize him, but molesting no indifferent spectators. As soon as he got inside the cafê, he took a bucket of water, raised it to his head, and poured over it all the water, as if to convince the lookers-on that he was no longer suffering from hydrophobia, but that he was 
enraged against the gens-d'armes, who wished to poison him. In the mean while some gens-d'armes and policemen seized him, and, holding him fast, enveloped him in carpets, rolled him on the ground, and when he was well bound placed him on a cart, and carried him into the Church, where he was shut up and guarded by the gens-d'armes. He died in a state of frenzy, eighteen hours afterwards, on the 20th May.

I am induced to ask the following questions: May hydrophobia, the characteristic and inseparable symptom of canine madness, if once developed, disappear, and the disease nevertheless continue, and destroy the patient? Or does the disappearance of this symptom justify the hope of perfect recovery (putting aside the gens-d'armes)! Can the cessation of the hydrophobia in the preceding case be attributed to the use of the asparagus?

With reference to the last question, I have to cite my experience in three other cases. The patients were women; all had been bitten by dogs undoubtedly mad. The two first I saw in Canada; they were completely cured under the use of asparagus alone; but in both cases the symptom of hydrophobia was wanting, and I no longer expected it, inasmuch as there already existed numbness of the bitten part, ptyalism, and burning in the throat. The third case occurred in Athens; the woman suffered from hydrophobia in the highest degree. She died before the asparagus administered could reach the stomach. I was only summoned at the last moment.

I conclude that the physician who is unprovided with better means ought to try asparagus in these cases. Should experience prove the efficacy of this remedy, I trust that no government and no society will deprive me of the credit of this discovery.

Athens, May, 1853.

\section{A flírror}

OF THE PRACTICE OF

\section{MEDICINE AND SURGERY IN THE}

HOSPITALS OF LONDON.

Nulla est alia pro certo noscendi via, nisi quam plurimas et morborum, et dissectionum historias, tam aliorum pro

\section{ST. GEORGE'S HOSPITAL.}

Tumour in the Right Hypochondriac Region; Numerous Abscesses of the Liver; Death; Autopsy.

(Under the care of Dr. Wruson.)

The formation of an abscess is a very common pathological event, which is not in general looked upon as a serious deviation from health; yet how fearful this simple manifestation may become when it arises in organs or regions of vital importance! As a rule, the most perilous consequences may be expected when a purulent accumulation takes place in any of the three cavities, and of such an occurrence we have of late had occasion to offer two examples: one of the patients was under the care of Dr. Gull, at Guy's, (The LAxoet, vol. ii. 1853, p. 77, and the other under the care of Dr. Todd, at King's College, (Tix LancrT, vol. ii. 1853, p. 7.) In these two eases the existence of abscess remained unsuspected during life, nor was, in the one to which we now wish to direct attention, the formation of pus looked upon as the principal symptom.

It is, indeed, a fact of great interest, and very useful to remember, that the most radical changes may go on for a long time in some of the principal organs without exciting very striking symptoms, provided these changes take place very gradually; whereas sudden effusions, the presence of foreign bodies, the retention of some excretion, \&c., at once disturb the equilibrium of the system, and are quickly followed by a stand-still of the elaborate human machinery. As an instance of the latter circumstance, we might quote a case (reported in last week's " Mirror") of acute ulceration of a portion of the aortic valves; and we hope soon to publish a still more instruetive case of the kind, (also under the care of Dr. Burrows, ) viz., an enormous distension of the pericardium caused by a sudden effusion in its cavity, unconnected with rheumatism. Let us for the present turn to the somewhat obscure case nnder the care of Dr. Wilson, taking advantage of the notes of Dr. Barclay, the medical registrar.

Ann M-a a - aged forty five years, was admitted Dec. 29, 1852 The patient complained of a tumour in the right hypochondrium, which she had observed about three months prior to admission. Two months before perceiving this tumour, she had had pain in the same region, which pain was ascribed to inflammation of the liver. There was, however, no jaundice, but the appetite declined, emaciation set in, and the pain rapidly increased. On examination, a firm, rounded tumour was found occupying the right lumbar region; this tumour appeared immovable, and seerned continuous with the liver, but separated from that organ by a rather deep sulcus; the hepatic dulness extended over the growth in a modified degree, deep resonance of a lower tone being heard on percussion. The actual nature of this tumour was not apparent, but it was plain that the liver had been the seat of pathological changes of serious import, either abscess or malignant disease having in all probability sprung up in it. Leeches were applied, and the patient took during the day iodide of potassium and colchicum, and at night, an antimonial saline draught. The leeches relieved the pain, but no change occurred in the character of the tumour, which remained immovable, presented no fiuctuation, and did not seem to have any connexion with the pelvic or iliac regions. The patient, however, became sallow and thin; her skin at last assumed a yellow tinge, and she died March 16, 1853, ten weeks after admission. The post-mortem examination was conducted by Mr. Gray, one of the conservators of the museum, twenty-one hours after death. The body was well formed but thin; the skin and the conjunctiva of both eyes were of a yellow tinge.-Thorax: The Inngs were healthy, excepting a slight amount of emphysema: the heart was also quite sound.

On opening the cavity of the abdomen, there was found a tumour about the size of the closed fist, connected with and partly contained in the substance of the right lobe of the liver, at its anterior border. 'The peritoneum covering the abdominal parietes was intimately adherent to the anterior part of the tumour; and the ascending portion of the duodenum, where it passes in relation with the under surface of the liver, as well as the right transverse arch of the colon, were firmly matted together, and also to the under surface of the abnormal growth. The latter had likewise implicated the gall-bladder, the whole of which, together with the cystic duct, were entirely destroyed. On section, the tumour presented a grayish-white colour; its circumference was very firm, but the central part softer, and of a pultaceous consistence, not unlike the solid matter left after the absorption of the fluid part of a purulent collection. The whole of the substance of the right lobe of the liver was riddled throughout with numerous abscesses of various size, but the left lobe was quite healthy. In the common choledic duct was found a biliary calculus as large as a nut; above this point the duct was much dilated, and the dilatatation was not confined to the duct alone, but was observed in the smaller ramifications throughout the whole organ. The stomach and intestinal canal, as well as the pelvic viscera, were quite healthy.

As the hepatic tumour above mentioned presented no characters of malignancy, it may perhaps be inferred that this case was one of idiopathic abscess of the liver, preceded by severe inflammation, which inflammation gave rise to considerable fibrinous deposit. Suppuration seems to have become subsequently established, in the form of numerous abscesses in the right lobe of the liver, and of central softening of the tumour. This view, although founded merely on analogy and probabilities, nevertheless suggests a train of remarks, the principal of which is, whether the development of the morbid changes in this case could, at the outset, have been arrested by vigorous therapentical measures. Perhaps they might; but we rarely have an opportuvity of testing this question in hospital practice, as patients seldom apply for relief until the period during which acute inflammation might successfully be combated is completely over.

Dr. Budd has shown, in his work on the Diseases of the Liver, that the acrid secretions from intestinal ulceration, so common in dysentery, may excite inflammation and abscess in the liver; and numerous cases have been brought forward in support of this theory; but the present seems to be of the purely idiopathic kind, the inflammation having been very intense, if we may judge from the abundant fibrinous exudation, and the matting together of the viscera situated in the vicinity of the liver. This fact brings to our recollection a 